\title{
Microvascular free-flap transfer for head and neck reconstruction in elderly patients
}

\author{
Francesco Turrà', Simone La Padula', Sergio Razzano', Paola Bonavolontà2, Gisella Nele', Sergio Marlino', \\ Luigi Canta', Pasquale Graziano², Giovanni Dell'Aversana Orabona², Fabrizio Schonauer ${ }^{1 *}$ \\ From 26th National Congress of the Italian Society of Geriatric Surgery \\ Naples, Italy. 19-22 June 2013
}

\begin{abstract}
Background: With the increase in life expectancy, the incidence of head and neck cancer has grown in the elderly population. Free tissue transfer has become the first choice, among all the reconstructive techniques, in these cases. The safety and success of micro vascular transfer have been well documented in the general population, but its positive results achieved in elderly patients have received less attention.

Methods: We retrospectively studied 28 patients over the age of 60 years. The aim of this paper was to study the success rate of free tissue transfer and investigate the complication incidence in this patient population.

Results: Twenty-eight free flaps were performed to reconstruct medium to large cervico-facial surgical defects in six years. No difference was noted between success and complication rates observed between general and elderly population.

Conclusion: This study indicates that free-flap technique for head and neck reconstruction could be considered a safe option in elderly patients when a good pre-operative general status is present.
\end{abstract}

\section{Background}

Microsurgical free-tissue transfer has gained a central role in plastic surgery for difficult reconstruction of head and neck defects, modifying the treatment of cancer in this region.

Although this technique has become a safe choice, complications may occur in 5-25\%; these patients may require a surgical re-exploration of the free flap [1].

The proportion of elderly people with head and neck cancer is rising due to an overall increase in life expectancy.

The safety and success of free flap transfer have been well documented in the general population; positive results achieved in elderly patients have received less attention [2].

The aim of the present study is to investigate the effect of age on the outcome of such procedures, the medical impact of prolonged surgery and if it is worthy

\footnotetext{
* Correspondence: fschona@libero.it

'Unit of Plastic, Reconstructive and Aesthetic Surgery, Federico II University, Via S.Pansini 5, 80131, Naples, Italy

Full list of author information is available at the end of the article
}

against the functional benefits and the better life expectancy achieved by the use of microvascular reconstruction.

\section{Methods}

We retrospectively reviewed our experience with microsurgical free-tissue transfer in patients over the age of 60 whom we arbitrarily defined as "elderly".

Between January 2007 and February 2013, 28 patients with head and neck cancer were treated at the Maxillofacial Surgical Unit and reconstructed by our Plastic Surgery team.

The patients were classified into two groups according to age: between 60 and 69 years (age group I) and between 70 and 79 years (age group II), respectively. Table 1.

The oral cavity was the most frequent site of reconstruction in all groups. All patients undergoing microsurgical free-tissue transfer were recovered in intensive care unit until their stabilization. The flap was monitored by checking paddle skin colour, bleeding and, if necessary, Doppler signal, every 2 hours for the first day, every $6 \mathrm{~h}$

\section{(Ciomed Central}


Table 1 Patient series

\begin{tabular}{|c|c|c|c|c|c|c|c|c|}
\hline Name & Age & Group & ASA & Type of tumour & Site & Reconstruction & Days in Intens.Care & Complications \\
\hline $\mathrm{PO}$ & 60 & 1 & 1 & SCC & Cheek & Radial forearm & 1 & - \\
\hline AR & 60 & । & 2 & Sarcoma & Mandible & Fibula osteocutaneous & 1 & Venous throbosis \\
\hline GE & 61 & । & 1 & SCC & Mandible & Fibula osteocutaneous & 2 & - \\
\hline$A G$ & 62 & । & 1 & SCC & Palate & Radial forearm & 1 & - \\
\hline MD & 62 & । & 2 & SCC & Tongue & Radial forearm & 1 & - \\
\hline PM & 63 & । & 2 & SCC & Larynx and pharynx & Radial forearm & 2 & - \\
\hline TD & 64 & । & 1 & $\mathrm{BCC}$ & Cheek (ext.) & Radial forearm & 1 & - \\
\hline CG & 65 & । & 2 & SCC & Scalp & Latissimus dorsi & 1 & - \\
\hline FS & 65 & । & 1 & SCC & Cheek (ext.) & Latissimus dorsi & 1 & - \\
\hline DA & 66 & । & 2 & SCC & Tongue & Ulnar forearm & 1 & - \\
\hline AP & 66 & । & 2 & SCC & Tongue & Ulnar forearm & 1 & - \\
\hline DR & 66 & । & 1 & SCC & Floor and tongue & Radial forearm & 1 & - \\
\hline DN & 67 & । & 1 & SCC & Floor and tongue & Radial forearm & 1 & - \\
\hline SA & 68 & । & 2 & SCC & Cheek & Radial forearm & 1 & - \\
\hline IB & 69 & । & 1 & SCC & Pharynx & Radial forearm & 2 & - \\
\hline BM & 70 & $\|$ & 2 & SCC & Floor & Radial forearm & 1 & - \\
\hline DC & 70 & $\|$ & 1 & SCC & Mandible & Fibula osteocutaneous & 2 & - \\
\hline RA & 71 & $\|$ & 1 & SCC & Lips and cheek & Radial forearm & 1 & - \\
\hline PA & 72 & $\|$ & 3 & SCC & Tongue & Radial forearm & 3 & Pulmonary failure \\
\hline RM & 72 & $\|$ & 2 & SCC & Floor and tongue & Radial forearm & 1 & - \\
\hline$C R$ & 72 & $\|$ & 1 & SCC & Scalp & Latissimus dorsi & 2 & - \\
\hline SG & 73 & $\|$ & 2 & SCC & Cheek & Radial forearm & 1 & Haematoma \\
\hline SM & 75 & $\|$ & 1 & SCC & Tongue & Radial forearm & 1 & - \\
\hline FS & 75 & $\|$ & 2 & SCC & Mandible & Fibula osteocutaneous & 2 & Partial necrosis \\
\hline DM & 75 & $\|$ & 1 & SCC & Floor and tongue & Radial forearm & 1 & - \\
\hline $\mathrm{Pl}$ & 76 & $\|$ & 2 & SCC & Half right face & Rectum abodminis muscle & 3 & Venous thrombosis \\
\hline GG & 77 & $\|$ & 2 & SCC & Half right face & Rectum abodminis muscle & 2 & - \\
\hline TC & 77 & $\|$ & 1 & SCC & Floor and tongue & Radial forearm & 1 & - \\
\hline
\end{tabular}

on day 2-3 and then less frequently until patient's discharge.

Many variables were analysed for each group. Our records were reviewed searching for diagnosis, free-flap type, defect site, patient age and sex, preoperative medical problem, length of operation, complications and operative mortality. We classified complications into two main clusters: technique-related (seroma, haematoma, infection, dehiscence, thrombosis, congestion and skin or flap loss) and general conditions-related. Technique complications were classified as major, requiring surgical re-exploration, or minor, not requiring reexploration.

Long-term functional outcomes (speech, swallowing and chewing) were assessed 6 month after surgery.

\section{Results and discussion}

A total of 28 patients ( 20 male, 8 female; ranging 60 to 77 years) underwent a free-tissue transfer for head and neck tumours. Fifteen patients, were aged between 60 and 69 years (age group I) and thirteen patients were aged between 70 and 79 years (age group II).
Most frequent histological diagnosis, preoperatively indicated by biopsy, was squamous cell carcinoma.

Various free flap types were used to reconstruct a variety of defects. Microvascular free flaps used were: radial forearm $(\mathrm{n}=17)$, fibula $(\mathrm{n}=4)$, latissimus dorsi $(\mathrm{n}=3)$, ulnar forearm $(\mathrm{n}=2)$, rectus abdominis $(\mathrm{n}=2)$. Total success rate was $93 \%(26 / 28)$.

Preoperative medical problems were evaluated through American Society of Anesthesiologists (ASA) score; just one patient classified as ASA III class underwent microvascular technique.

Donor site major complications were not observed.

Total complication rate was $17,9 \%$ (5/28); complications were divided into two different groups: technique-related and systemic condition-related. Four technique-related complications were observed (14,3\%): of these three were major and one minor. Major flap complications (10,7\%) consisted of one venous thrombosis of the pedicle and one partial necrosis in age group II $(15,4 \%)$ and one venous thrombosis in age group I (6,7\%). Flap salvage was possible in the younger patient with venous thrombosis by exploring the flap and performing a new anastomosis; in the 
older patient with partial necrosis another local flap was needed; total flap loss occurred in another case.

A minor flap complication occurred in the age group II (7,7\%): an haematoma occurred at the recipient site and was evacuated at the patient bed, with no surgical re-exploration.

One patient, in the age group II, had a systemic complication that resulted in respiratory failure soon after the transfer to the intensive care unit. This patient with COPD was an heavy smoker.

Speech, swallowing and chewing assessed in our patients 6 months after surgery resulted well preserved.

Head and neck tumours are often diagnosed late, because of their lack of symptoms in the early stage. In these cases a large demolition is needed. Because of the importance of the quality of life, surgery has to be safe and give satisfactory functional outcomes. Microvascular freetissue transfer has gained a central role for these large reconstructions to protect important functions of this region. The success rate of this surgery at the present time is reported to be in the range of $91 \%$ to $99 \%$ in large series from major microsurgical centers [3-5].

Age has been regarded frequently as an independent risk factor for bad surgical outcomes; before the 1960s the mortality rate for elderly patients undergoing elective surgery was 2-6 times higher than in the general population [6]. The reasons that may explain this difference are well documented; the most common medical problems that affect the mortality are heart failure, or the compromise of pulmonary function $[7,8]$.

The improvements in anaesthesia techniques explain the reduction of the mortality rate in elderly patients during these 40 years, especially for patients with cardiac disease [9].

Studies on microsurgical free flap conducted in elderly patients do not agree in defining the term "elderly", but they demonstrated that age is not an important factor influencing the success of this surgery [10-13]. Pompei et al. in a large study of pedicled and free flaps for head and neck reconstructions showed that complications were related with comorbidities more than the age [14].

A reliable predictor of postoperative morbidity could be the ASA status as suggested in a study by Serletti et al. [13].

However, these studies stress how several factors can lead to free-flap complication; most of them reported that age does not impact the free transfer success, but results are variable.

Our results are comparable to the ones showed by Shestak et al. in their small series of cases. In this study 19 patients underwent a free flap reconstruction and results showed a $16 \%$ major surgical complication rate in patients over 70 years and $13 \%$ in patients under 70 years [10].
In the present study one patient died after this surgery (mortality rate $3,5 \%$ ); this fatal post-operative complication was correlated with a higher ASA class.

\section{Conclusion}

In conclusion our study shows that microsurgical freeflap transfer can be considered a safe technique for head and neck reconstruction in all age groups. Pre-existing systemic disease could influence peri- and post-operative complications, and ASA status could be a well accepted way to select patients undergoing this surgery.

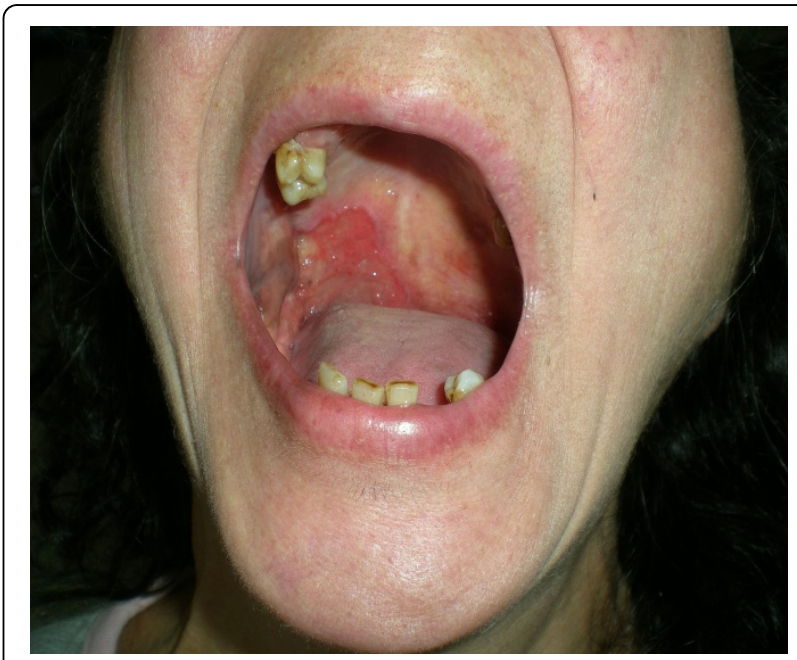

Figure 1 Squamous cell carcinoma of the right cheek and tonsillar pillar.

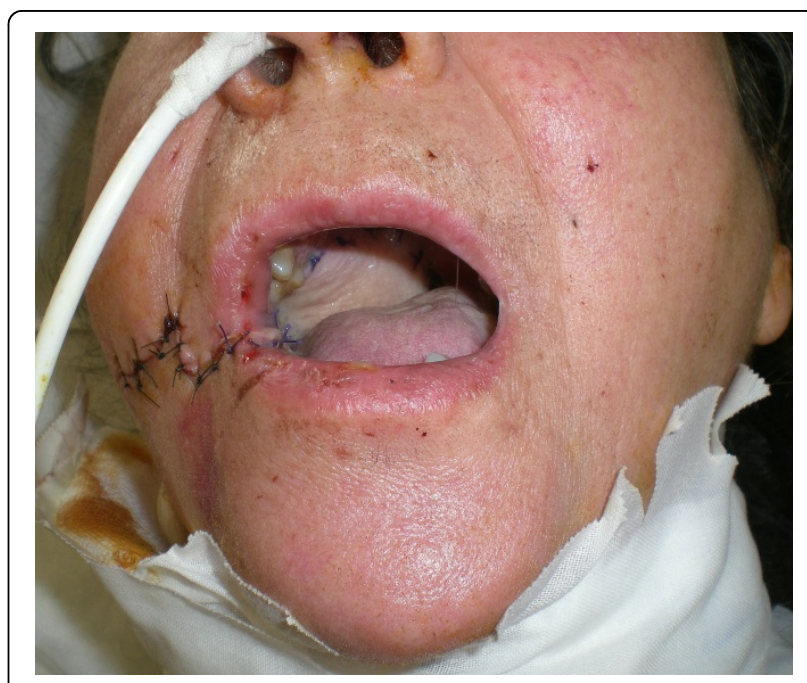

Figure 2 Transferred radial forearm free flap at two weeks. 


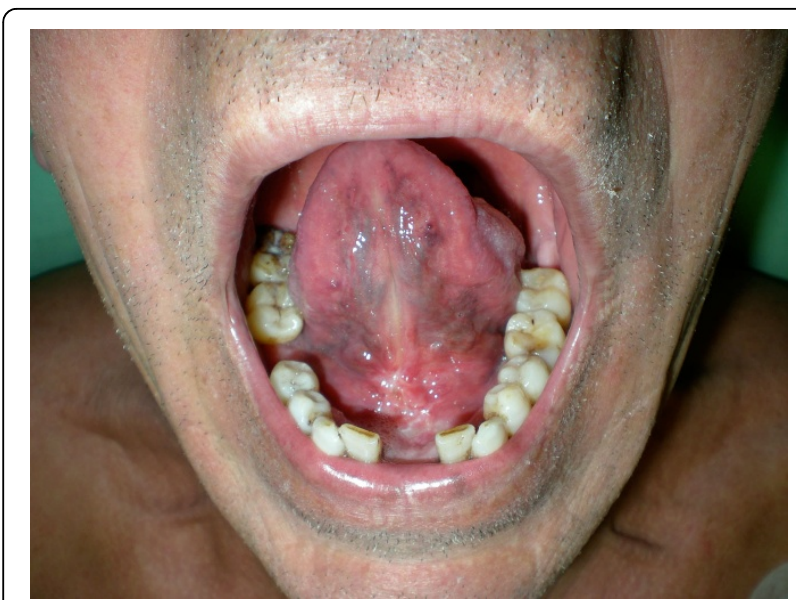

Figure 3 Squamous cell carcinoma of the floor of the mouth.

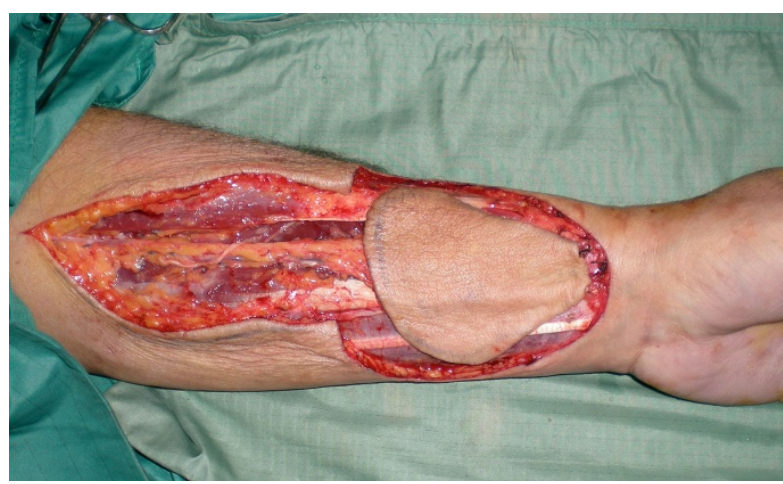

Figure 4 Radial forearm free flap harvesting and its pedicle.

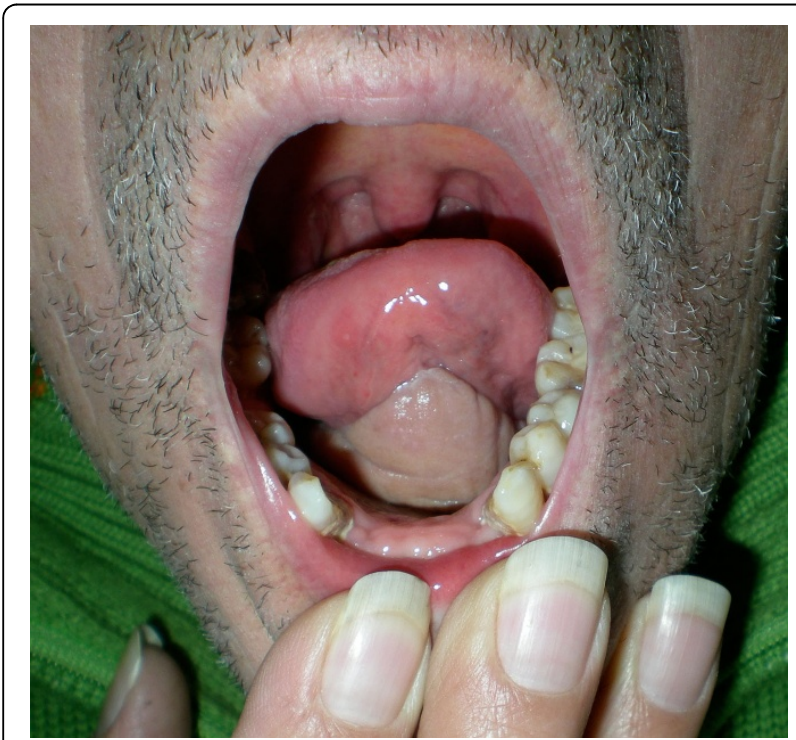

Figure 5 Settled radial forearm free flap at 6 months follow-up

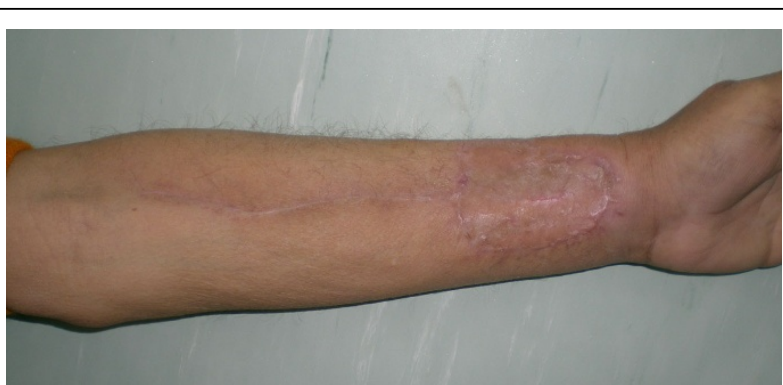

Figure 6 Healed skin grafted radial forearm free flap donor site 6 months after surgery.

\section{List of abbreviations used}

$\mathrm{ASA}=$ American Society of Anesthesiologists; $\mathrm{COPD}=$ Chronic Obstructive Pulmonary Disease; SCC= Squamous Cell Carcinoma; BCC= Basal Cell Carcinoma.

\section{Competing interests}

The authors declare that they have no competing interests.

\section{Authors' contributions}

F.T.: conception and design, acquisition and interpretation of data, drafting the manuscript, given final approval of the version to be published. S.L.P.: acquisition of data, given final approval of the version to be published. S.R.: interpretation of data, drafting the manuscript, given final approval of the version to be published. P.B, S.M, L.C, P.G: critical revision, interpretation of data, given final approval of the version to be published. G.N.: drafting the manuscript, given final approval of the version to be published. G.D.A.O.: acquisition and interpretation of data, critical revision, given final approval of the version to be published. F.S.: conception and design, acquisition and interpretation of data, drafting the manuscript, critical revision, given final approval of the version to be published.

\section{Authors' information}

FT: Medical Doctor. SLP: Resident in Plastic, Reconstructive and Aesthetic Surgery at University Federico II, Naples. SR: Resident in Plastic,

Reconstructive and Aesthetic Surgery at University Federico II, Naples. PB: Resident in Maxillofacial Surgery at University Federico II, Naples. GN: Medical Student. SM: Resident in Plastic, Reconstructive and Aesthetic Surgery at University Federico II, Naples. LC: Specialist in Plastic, Reconstructive and Aesthetic Surgery at University Federico II, Naples. PG: Specialist in Maxillofacial Surgery at University Federico II, Naples. GDAO: Assistant Professor in Maxillofacial Surgery at University Federico II, Naples. FS: Assistant Professor in Plastic, Reconstructive and Aesthetic Surgery at University Federico II, Naples

\section{Declarations}

Publication of this article was funded by research university funding. This article has been published as part of BMC Surgery Volume 13 Supplement 2, 2013: Proceedings from the 26th National Congress of the Italian Society of Geriatric Surgery. The full contents of the supplement are available online at http://www.biomedcentral.com/bmcsurg/supplements/13/ S2.

\section{Authors' details}

${ }^{1}$ Unit of Plastic, Reconstructive and Aesthetic Surgery, Federico II University, Via S.Pansini 5, 80131, Naples, Italy. ${ }^{2}$ Department of Maxillofacial Surgery, Federico II University, Via S.Pansini 5, 80131, Naples, Italy.

Published: 8 October 2013

\section{References}

1. Salgado CJ, Moran SL, Mardini S: Flap monitoring and patient management. Plast Reconstr Surg 2009, 124(6 suppl):e295-e302. 
2. Yu P, Chang DW, Miller MJ, et al: Analysis of 49 cases of flap compromise in 1310 free flaps for head and neck reconstruction. Head Neck 2009, 31:45-51.

3. Shaw WW: Microvascular free flaps: the first decade. Clin Plast Surg 1983 10:3.

4. Khouri RK: Free flap surgery: the second decade. Clin Plast Surg 1992, 19:757.

5. Hidalgo DA, Jones CS: The role of emergent exploration in free-tissue transfer: A review of 150 consecutive cases. Plast Reconstr Surg 1990, 86:492.

6. Cole WH: Prediction of operative reserve in the elderly patient. Ann Surg $1968,168: 310$

7. Guarnieri T, Filbrun CR, Zitnik G, et al: Contractile and biochemical correlates of b-adrenergic stimulation of the aged heart. Am J Physiol 1980, 239:H501-8.

8. Mannino DM, Davis KJ: Lung function decline and outcomes in elderly population. Thorax 2006, 61:472-7.

9. Foster ED, Davis KB, Carpenter JA, et al: Risk of noncardiac operation in patients with defined coronary disease. Ann Thorac Surg 1986, 41:42-50.

10. Shestak KC, Jones NF: Microsurgical free-tissue transfer in the elderly patients. Plast Reconstr Surg 1991, 88:259-63.

11. Bonawitz SC, Schnarrs RH, Rosenthal Al, et al: Free tissue transfer in elderly patients. Plast Reconstr Surg 1991, 87:1074-79.

12. Ziffren SE, Hartford CE: Comparative mortality for various surgical operations in older versus younger age group. J Am Geriatr Soc 1972, 20:485-9.

13. Classen DA, Ward H: Complications in a consecutive series of 250 free flap operations. Ann Plast Surg 2006, 56:557-61.

14. Pompei $S$, Tedesco M, Pozzi $M$, et al: Age as a risk factor in cervicofacial reconstruction. J Exp Clin Cancer Res 1999, 18:209-12.

doi:10.1186/1471-2482-13-S2-S27

Cite this article as: Turrà et al:: Microvascular free-flap transfer for head and neck reconstruction in elderly patients. BMC Surgery 2013

13(Suppl 2):S27.

\section{Submit your next manuscript to BioMed Central} and take full advantage of:

- Convenient online submission

- Thorough peer review

- No space constraints or color figure charges

- Immediate publication on acceptance

- Inclusion in PubMed, CAS, Scopus and Google Scholar

- Research which is freely available for redistribution

Submit your manuscript at www.biomedcentral.com/submit
Ciomed Central 